\title{
Recuperação de nascentes: Formação de multiplicadores ambientais em área degradada de Assentamento rural, Eldorados dos Carajás, Pará
}

\section{Recovery of springs: Formation of environmental multipliers in degraded area of Rural Settlement, Eldorados dos Carajás, Pará}

\author{
Ariel Medrado Barros ${ }^{1}$; Camila de Oliveira Chaves ${ }^{2}$; Gleidson Marques Pereira ${ }^{3}$
}

\begin{abstract}
Resumo: No sudeste paraense, as frentes agropecuárias e mineradoras quando inseridas na base produtiva do estado, potencializaram a exploração dos recursos naturais disponíveis na região, o que elevou os níveis de degradação ambiental. Desta forma, objetivou-se recuperar nascentes degradadas e a identificar mudanças na percepção ambiental dos produtores rurais do Projeto de Assentamento 17 de Abril, Eldorado dos Carajás, Pará. O trabalho foi desenvolvido em cinco propriedades, as quais suas nascentes foram selecionadas a partir de explanações e debates relacionados ao processo de recuperação ambiental. A área ao entorno de cada nascente foi caracterizada através dos seguintes parâmetros: predominância de cobertura vegetal; ocorrência de processos erosivos no solo; uso de agrotóxicos; presença de animais de criação; evidências de queimadas ou de corte da vegetação; e ocorrência de edificações domésticas e/ ou rurais. A técnica de recuperação e preservação de nascentes utilizada foi a solo-cimento. Um questionário foi aplicado aos proprietários dos lotes com a finalidade de compreender a dinâmica e cultura local e a de que forma a recuperação da nascente modificou ou possa vir a modificá-las. Os resultados apontam o envolvimento dos agricultores e seus familiares com o trabalho executado. A técnica de recuperação e conservação das nascentes foi concebível, visto que, aliado ao isolamento, apresenta eficiência na vedação, o que evita a contaminação da água. Ocorreram mudanças na percepção ambiental dos agricultores, além de melhorias socioambientais.
\end{abstract}

Palavras-chave: Degradação ambiental; Educação ambiental; Recuperação ambiental; Solo-cimento.

\begin{abstract}
In Southeast Pará, the agricultural and mining fronts, when inserted in the productive base of the state, increased the exploitation of natural resources available in the region, which raised the levels of environmental degradation. In this way, the objective of this work is to recover degraded springs and to identify changes in the environmental perception of the rural producers of the Settlement Project April 17, Eldorado dos Carajás - Pará. The work was developed in five properties, whose sources were selected from explanations and debates related to the environmental recovery process. The area around each spring was characterized by the following parameters: predominance of vegetation cover; occurrence of erosive processes in the soil; use of agrochemicals; presence of farm animals; evidence of burning or vegetation cutting; and occurrence of domestic and / or rural buildings. The technique of recovery and preservation of the springs used was the soil-raising. A questionnaire was applied to the lot owners in order to understand the local dynamics and culture and how the spring recovery modified or could modify them. The results indicate the involvement of farmers and their families with the work performed. The technique of recovery and conservation of the springs was conceivable, since, together with the insulation, it presents efficiency in the seal, which avoids the contamination of the water. It was verified that there were changes in farmers' environmental perception, as well as socioenvironmental improvements.
\end{abstract}

Key words: Environmental degradation; Environmental education; Environmental recovery; Soil-cement.

\footnotetext{
*Autor para correspondência

Recebido para publicação em 29/03/2016; aprovado em 28/09/2017

${ }^{1}$ Graduação em Engenharia Ambiental pela Universidade do Estado do Pará, campus Marabá, Pará. E-mail: arielmedrado@gmail.com

${ }^{2}$ Graduação em Engenharia Ambiental pela Universidade do Estado do Pará, campus Marabá, Pará. E-mail: eng.oliveirachaves@ gmail.com

${ }^{3}$ Mestrado em Agronomia - Solos e Nutrição de Plantas pela Universidade Federal do Ceará. Docente do curso de Engenharia Ambiental da Universidade do

Estado do Pará, campus Marabá, Pará. E-mail: agro_gleidson@yahoo.com.br
} 


\section{INTRODUÇÃO}

O Brasil, nas últimas décadas, passou por um processo de desenvolvimento sem planejamento adequado, o que comprometeu a qualidade ambiental, devido às necessidades cada vez maiores de produção de alimentos e consumo energético. Essas demandas implicam na gestão sustentável do meio ambiente, pois os recursos naturais disponíveis são diariamente explorados de forma desenfreada, o que pode ocasionar na deterioração irreversível destes bens.

Especificadamente no sudeste paraense, as frentes agropecuárias e mineradoras, quando foram inseridas na base produtiva do estado, potencializaram a exploração dos recursos naturais disponíveis na região, o que elevou os níveis de degradação ambiental. Percebe-se, então, que a expansão dessas atividades na Amazônia, além de provocar degradação, representa um palco de intensos conflitos agrários decorrentes da concentração fundiária. E, nessa perspectiva, o surgimento de assentamentos pelo Programa de Reforma Agrária muitas vezes ocorre sem adequado planejamento para uso da terra.

Nesse sentido, o uso das terras para a agricultura sem o manejo adequado, como ocorre em Projetos de Assentamento (PA), tem como consequência o desequilíbrio ambiental, a redução da qualidade produtiva das terras e o comprometimento da disponibilidade hídrica. No entanto, a ideia de degradação ambiental relacionada às atividades agrícolas, poucas vezes é entendida, pelos produtores rurais assentados, como uma atividade hostil ao solo, às matas e às nascentes.

Assim, é imprescindível a utilização de estratégias de preservação das nascentes, considerando o valor econômico e social inapreciável da água, para desenvolver sua função em propriedades rurais. A disponibilidade é determinante no êxito das atividades agrícolas e na qualidade de vida dos agricultores, que consomem água diretamente dos olhos d'água.

A recuperação de nascentes, que representa uma estratégia de preservação, para o agricultor, traz inúmeros benefícios, como o aumento da produtividade de alimentos e a geração de renda. Entretanto, os impactos ambientais decorrentes do manejo inadequado do solo e dos recursos hídricos podem provocar sérios efeitos deletérios, como redução da disponibilidade hídrica, degradação da mata ciliar, processos erosivos, entre outros, e, consequentemente, conflitos pelo uso da água.

Diante desta problemática, sobretudo a dos mananciais de água potável, é profundamente importante preservar a água desde sua nascente, para que haja garantia de qualidade para o consumo. $\mathrm{O}$ acesso à água é um direito humano fundamental. Portanto, toda pessoa deve ter água potável em quantidade suficiente, com custo acessível e fisicamente disponível, para usos pessoais e domésticos, conforme previsto na legislação brasileira (SANTOS; CRISPIM, 2011).

Desta forma, a aplicação de técnicas voltadas para recuperação e preservação de nascentes, propicia à população assentada acesso e disponibilidade de água suficiente para o consumo e utilização em atividades agrossilvipastoris. Além disso, as nascentes recuperadas voltam a atuar no ciclo hidrológico e, consequentemente, contribuirão com o equilíbrio da microbacia.

Nessa perspectiva, depreende-se que, em qualquer planejamento que objetiva a recuperação ou conservação de uma nascente, é necessário que sejam criadas condições favoráveis à infiltração da água no solo para que seja acumulada num aquífero e, posteriormente, abastecer uma ou mais nascentes associadas a esta. Aliada à recuperação, a ciência da agroecologia, definida como a aplicação de conceitos e princípios ecológicos ao desenho e manejo de agroecossistemas sustentáveis, proporciona o uso mais eficiente dos recursos hídricos disponíveis (CASTRO, 2015; ALTIERI, 2010).

Com relação ao processo de recuperação das bacias de cabeceira, independentemente do tipo e do estado de conservação da nascente a ser recuperada, o ponto de partida deve ser o isolamento da área num raio pré determinado pela legislação ambiental vigente, com a intenção de impedir a invasão por animais domésticos, evitando, principalmente, a compactação do solo pelo pisoteio e o comprometimento do estrato regenerativo da área.

A partir do supracitado, com relação ao processo de recuperação de nascentes, a técnica de construção de caixas protetoras, conhecidas como solo-cimento, consiste em uma técnica antiga que hoje é utilizada e bastante difundida em propriedades rurais (SANTOS; CRISPIM, 2011). E, de acordo com os relatos de diversos autores e os resultados observados, a técnica usando o solo-cimento é muito satisfatória, pois é possível um bom selamento, evitando que a água da nascente entre em contato com fatores externos que venham contaminá-la. Além disso, o método utiliza um material com alta durabilidade e ótima resistência, sem agredir o meio ambiente, o que contribui com a preservação dos recursos hídricos.

Assim, é essencial a utilização de mecanismos de educação ambiental, conforme previsto na legislação brasileira. A aplicação destes promove a integração do produtor rural acerca das questões ambientais, a construção de conhecimentos, habilidades, atitudes e competências associadas à conservação do meio ambiente, incluindo, a preservação das nascentes, que proporciona ganhos econômicos, sociais e ambientais.

A fim de ratificar o que está previsto na legislação, infere-se que a educação como prática ambiental favorece à tomada de consciência acerca da importância de avaliar os impactos ambientais referentes às atividades agrícolas (ZANZARINI, 2008).

Portanto, com base no exposto, o objetivou-se recuperar nascentes degradadas identificando mudanças na percepção ambiental dos produtores rurais do Projeto de Assentamento 17 de Abril, localizado no município de Eldorado dos Carajás, Pará.

\section{MATERIAL E MÉTODOS}

A área de estudo localiza-se no município de Eldorado dos Carajás, região Sudeste do Estado do Pará (Figura 1). Em relação à divisão político-administrativa limita-se ao Norte com o município de Marabá, a Leste com São Geraldo do Araguaia e Piçarra, ao Sul com Piçarra e a Oeste com Curionópolis. De acordo com o IBGE (2010), a população do município é de 31.432 habitantes. 
Figura 1. Localização geográfica do município de Eldorado dos Carajás, Estado do Pará

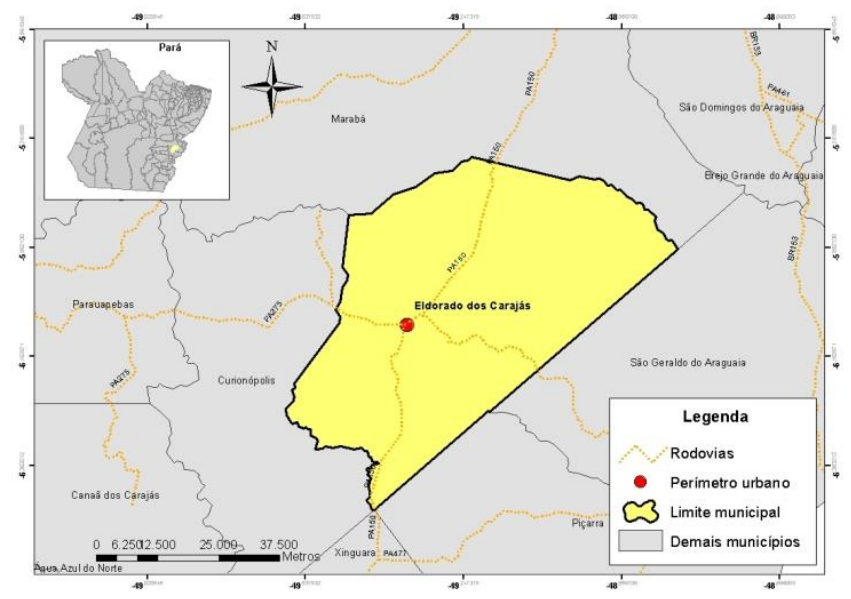

Fonte: Autor, 2015

Em um período de seis meses, compreendidos entre março e agosto do ano de 2015 , foram realizadas todas as etapas do trabalho, no Projeto de Assentamento 17 de Abril, Eldorado dos Carajás. Conforme De'Carli (2014), nesta área, cerca de 690 famílias estão assentadas em lotes de 25 hectares. O PA 17 de Abril é uma das maiores áreas da reforma agrária sobre a coordenação do Movimento dos Trabalhadores Sem Terra (MST) no Brasil, com cerca de
12.000 hectares, cadastrados pelo Instituto Nacional de Colonização e Reforma Agrária (INCRA).

Foram realizadas duas reuniões com os produtores rurais assentados, nas quais foram explanadas informações acerca das questões ambientais, como degradação de APP, práticas agroecológicas de cultivo, a importância das nascentes, sua recuperação e preservação, além da indicação dos possíveis benefícios a curto, médio e longo prazo, decorrentes do seu restabelecimento.

A partir do levantamento de dados e das reuniões com os produtores foram selecionadas cinco nascentes a serem estudadas. Os critérios de seleção utilizados foram a aceitação do produtor rural e a logística de transporte de materiais para o desenvolvimento da técnica de recuperação ambiental preestabelecida. O período de observação e identificação do estado de conservação das cinco nascentes ocorreu na primeira quinzena de março de 2015, quando foram realizadas visitas na área.

Assim, com base nos critérios preestabelecidos, foram selecionadas para o estudo as nascentes das propriedades de cinco produtores (Figura 2-A), identificados como P1, P2, P3, P4 e P5. Para a aplicação da técnica de recuperação, foi levada em consideração a logística de transporte, entre a Vila 17 de Abril e as propriedades rurais, dos materiais utilizados (Figura 2-B), pois foi o principal impasse identificado, o que inviabilizou a realização do processo em outros os lotes agrícolas.

Figura 2. Localização das nascentes estudadas no município de Eldorado dos Carajás, Estado do Pará. (A) Localização das nascentes estudadas: Produtor 1 (P1); Produtor 2 (P2); Produtor 3 (P3); Produtor 4 (P4); Produtor 5 (P5); (B) Localização das nascentes em relação à Vila 17 de Abril município de Eldorado dos Carajás, Estado do Pará

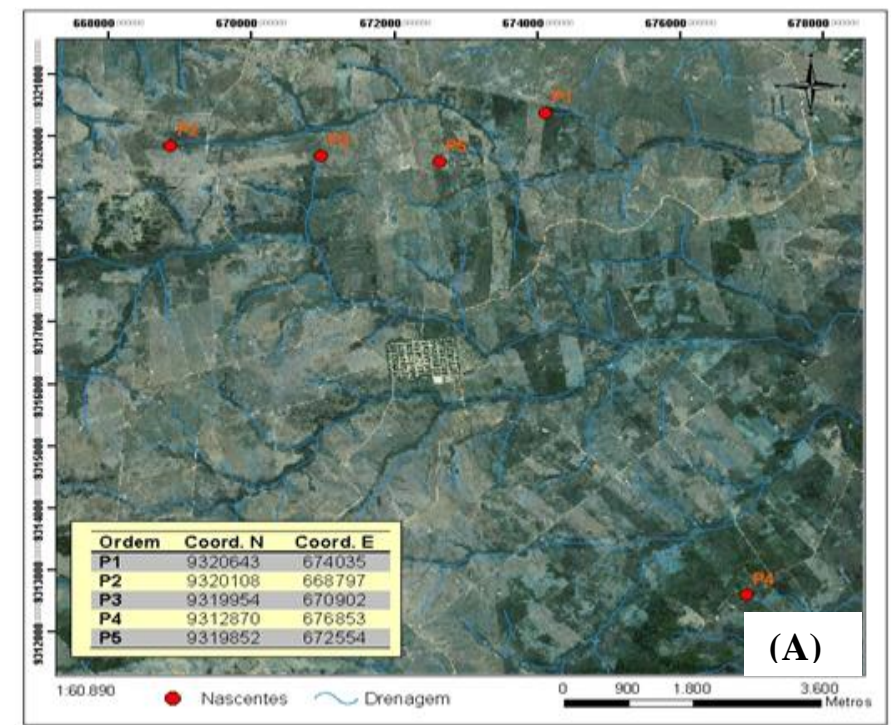

Fonte: Autor, 2015

Para a identificação do estado de conservação das nascentes selecionadas, os parâmetros utilizados foram os estabelecidos por Pereira (2012), que caracteriza o entorno das nascentes. Os parâmetros são: predominância de cobertura vegetal; ocorrência de processos erosivos no solo; uso de agrotóxicos; presença de animais de criação; evidências de queimadas ou de corte da vegetação; e ocorrência de edificações domésticas e/ou rurais.

Para o processo de recuperação e proteção das nascentes foram utilizados os seguintes materiais: fragmentos de rochas autóctones; enxada; pá pequena; três canos PVC de 50mm;

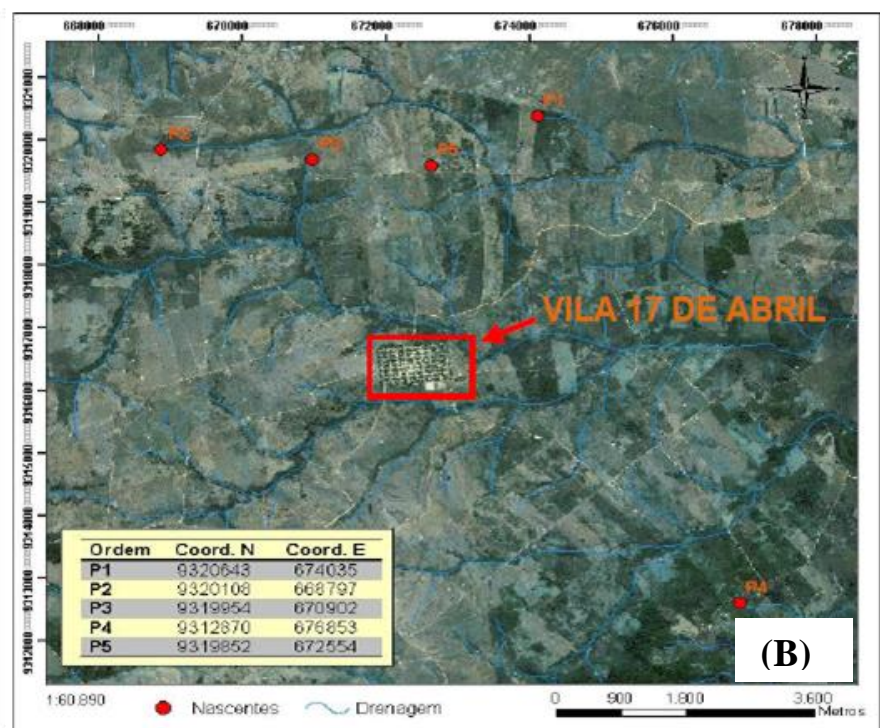

um cano PVC de 100mm; lona plástica; cimento e areia (Figura 3-A). A princípio foi realizado o isolamento da área ao entorno da nascente em um raio de 15 (quinze) metros, conforme estabelecido por Brasil (2012).

Em seguida, com o auxílio de uma enxada e uma pá, houve a limpeza manual da área das nascentes, retirando rochas, folhas e todo sedimento que obstruía o local onde brotava água, além da abertura de uma trincheira, por onde a água represada foi escoada (Figura 3-B). Uma área foi aberta ao redor do olho d'água (Figura 3-C) para o preenchimento 
posterior da caixa de coleta, que foi formada pela construção de uma pequena barragem.

Após a limpeza da área, foi construída uma barragem utilizando-se rochas autóctones (Figura 3-D). Próximos à superfície, com aproximadamente $20 \mathrm{~cm}$ de altura do ponto de queda de água da fonte, foi alocado o tubo PVC de 100 mm, cuja função é a limpeza da nascente. O tubo ficou aberto até o término da construção, pois permitiu escoamento da água sem que o desenvolvimento do trabalho fosse prejudicado. Em seguida, foi sobreposta mais uma camada de rochas, com largura proporcional à área aberta ao redor de onde brotava água e altura variável de acordo com a topografia do terreno.

Foram instalados canos PVC de $50 \mathrm{~mm}$, dois com funções de lançamento de água no curso natural hídrico no mesmo nível e o terceiro mais acima dos demais classificado de "ladrão", cuja função é escoar o excesso de água e evitar o rompimento da barragem. Nessa etapa, conforme a barragem foi sendo construída, a área entre ela e o local onde brotava água foi preenchido com fragmentos de rochas.

Em sequência, a estrutura construída foi coberta com lona plástica para impermeabilizá-la (Figura 3-E). E, por fim, com uma pá foi aplicada uma camada de solo-cimento, na proporção de três partes de solo para uma de cimento, sobre a lona plástica e a barragem de pedras. Por fim, após a aplicação do solo-cimento sobre toda a estrutura, quando o mesmo secou, o cano de limpeza $(100 \mathrm{~mm})$ foi vedado com o auxílio de um cap (Figura 3-F).

Figura 3. Etapas do processo de recuperação das nascentes. (A) Material utilizado; (B) Abertura da trincheira; (C) Identificação do olho d'água; (D) Construção da barragem com pedras alóctones junto à alocação dos tubos de PVC; (E) Impermeabilização da estrutura; (F) Estrutura finalizada após aplicação do solo-cimento.
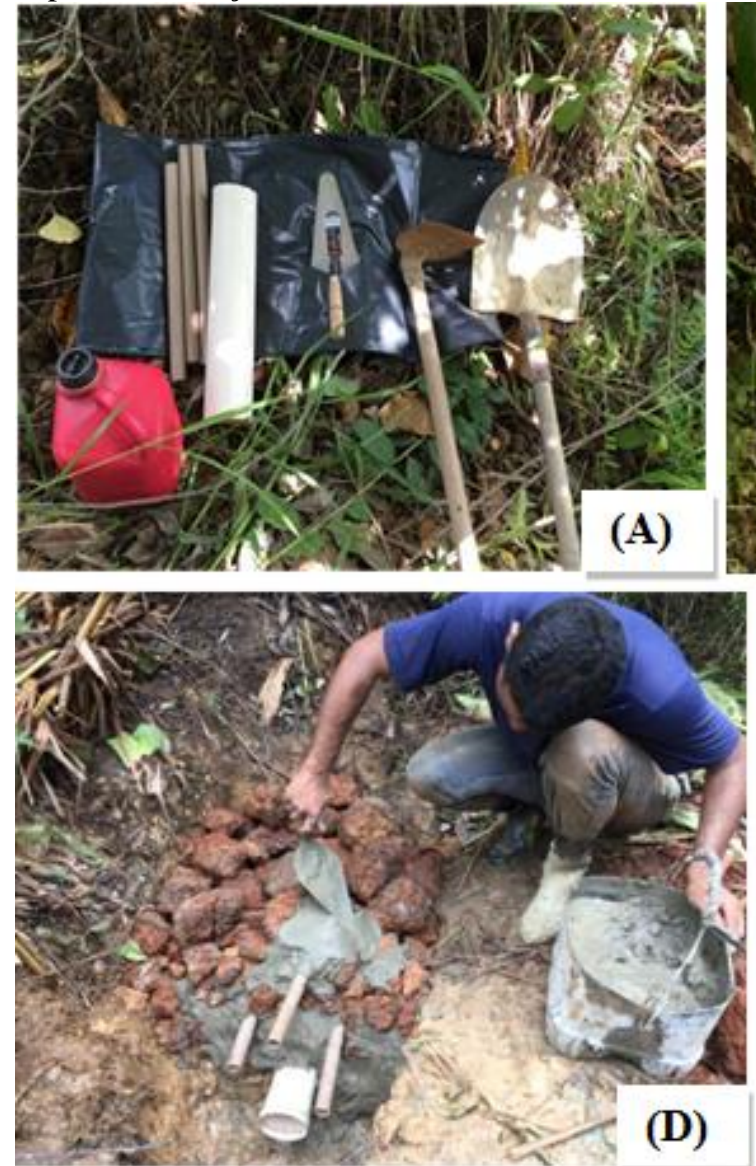

Fonte: Autor, 2015.

Para a identificação da percepção ambiental dos assentados, foi realizado levantamento acerca da realidade socioambiental do local. Esta identificação ocorreu por meio de observações visuais, entrevistas e aplicação de questionários aos proprietários dos lotes em estudo. O questionário aplicado foi do tipo misto, contendo questões de respostas objetivas e discursivas, o qual abordava, principalmente, a percepção quanto às possíveis problemáticas ambientais existentes na área, mesmo que superficialmente.

O questionário apresentava três eixos: informações sociais do assentado (número de moradores no lote, grau de parentesco, fonte de renda, entre outras); uso e ocupação do solo; informações gerais acerca das nascentes e a disponibilidade hídrica. O primeiro eixo foi para definir o perfil dos produtores da região e os demais para identificar as interferências existentes no meio ambiente.

A análise dos dados ocorreu em dois momentos distintos, antes e após à palestra e à aplicação processo de recuperação das nascentes. Os questionários foram analisados através da compilação das respostas análogas, ou seja, as esferas de análise surgiram com base nos eixos de abordagem e por intermédio dos dados que foram obtidos. 


\section{RESULTADOS E DISCUSSÃO}

As cinco nascentes recuperadas nos lotes agrícolas dos produtores rurais, como dispostas na Tabela 01 foram classificadas como pontuais, pois o fluxo de água ocorre em um único local do terreno, e perenes, uma vez que todos os proprietários das áreas que vivem no local relataram que as nascentes nunca "secaram", mesmo em períodos de estiagem. E, conforme Calheiros et al (2006), quando estão localizadas em encostas ou depressões do terreno e apresentam fluxo contínuo são assim consideradas.

Tabela 1. Identificação do estado de conservação no entorno das nascentes (por parâmetro observado em um raio de 50 m).

\begin{tabular}{cccccc}
\hline \multirow{2}{*}{ Parâmetros } & P1 & P2 & Pas & P4 & P5 \\
\cline { 2 - 6 } & SIM & SIM & NÃO & NÃO & NÃO \\
Cobertura vegetal & SIM & SIM & SIM & SIM & SIM \\
Processos erosivos & NĨO & SIM & SIM & NÃO & SIM \\
Uso de agrotóxicos & NIM & NÃO & SIM \\
Presença de animais de criação & NÃO & NÃO & SIM & NÃO & SIM \\
Queimadas e corte da vegetação & NÃO & NÃO & NÃO & NÃO & NÃO \\
Edificações domésticas ou rurais & NÃO & NÃO
\end{tabular}

Produtor 1 (P1); Produtor 2 (P2); Produtor 3 (P3); Produtor 4 (P4); Produtor 5 (P5)

Observa-se na tabala 1 as características das nascentes de acordo com cada parâmetro pré estabelecido para a identificação do estado de conservação de cada uma. De acordo com o resultado a maioria não possui mata ciliar ao redor do seu ponto de afloramento, salvo a presença de árvores de baixo porte em pequena quantidade.

A retirada da mata ciliar, de maneira geral, justifica-se pela necessidade da população em modificar as áreas de vegetação nativa para o uso alternativo do solo. É importante enfatizar que a grande maioria da vegetação existente no local é rasteira, característica típica de uma área de pastagem. Nesse sentido, Castro (2015), indicou como uma das causas da degradação de uma nascente o pastoreio intensivo, uma vez que o pisoteio de animais provoca, dentre outros fatores, a compactação do solo, o que reduz a capacidade de infiltração da água.

Assim, foi possível observar que o principal impacto gerado nas nascentes causado pelo pisoteio do gado foi a compactação do solo, o que impedia a drenagem superficial. Como consequência, o fluxo entre o córrego e o rio principal foi interrompido parcialmente, deixando de haver a alimentação frequente. Justifica-se, então, o motivo do cercamento. Na propriedade do $\mathrm{P} 2$, iniciou-se a realização do plantio de mudas típicas da região, fornecendo as condições de autorrecuperação da área.

Foi possível observar a presença de espécies exóticas como a braquiária (Brachiaria brizantha $\mathrm{cv}$ ), que impera na região do sudeste paraense sobre os solos de pastagem. De acordo com Brasil (2006) espécies exóticas são beneficiadas pela degradação ambiental, e são bem sucedidas em ambientes e paisagens alteradas. Isto posto, compreende-se que este é um importante obstáculo para o desenvolvimento dos planos de recuperação ambiental nestas regiões e soluções para este problema de manejo devem ser repensadas. Sabe-se que a retirada completa desta espécie nas áreas próximas ao córrego pode significar uma maior exposição do solo em uma atividade na qual ele precisa estar protegido para sua recuperação.

A respeito da importância da recuperação, contando com a compreensão e colaboração dos trabalhadores rurais do PA 17 de Abril, houve relevante ap4oio da população envolvida, o que contribuiu para que novas incursões fossem realizadas, a fim de esclarecer possíveis dúvidas acerca da atividade executada nas nascentes. O envolvimento dos familiares dos produtores ocorreu de maneira singular e a escolha do local de estudo, assim como a possibilidade de isolamento da área, somente foi possível em virtude da aprovação dos responsáveis dos lotes agrícolas, que se sensibilizaram acerca da importância do cumprimento da legislação ambiental referente à APP.

A conscientização dos produtores rurais assentados da região foi dificultada pelo isolamento das nascentes, estabelecido por Brasil (2012), que representa redução de área disponível, principalmente para a pecuária, pois a área, em duas propriedades (P3 e P5), são utilizadas para dessedentação e alimentação dos animais. No entanto, além do cumprimento da legislação, de acordo com Pinto et al. (2005), este cercamento evita a compactação do solo pelo pisoteio de animais e o comprometimento do estrato vegetal regenerativo da área, e estes fatores foram elencados, justificados e discutidos durante a palestra ministrada.

A educação ambiental, apesar das dificuldades encontradas, constituiu-se sobre a promoção da recuperação ambiental, integrando todos os elementos envolvidos na problemática. Desta maneira, destaca-se o pensamento de Minc (2005) que afirma um pensamento global e local implica na alimentação de grandes utopias, ampliação e utilização de conhecimentos científicos, além do estabelecimento de uma ampla frente de atuação, que possui a capacidade de converter desigualdades, agressões e desperdícios em práticas e atividades integradas por outros princípios, aliada a isto a natureza e a autonomia e liberdade de forma que se constituem elementos essenciais, com a finalidade de fundamentar as ações pontuais da pesquisa.

Nessa perspectiva, compreende-se que a partir de mudanças na percepção ambiental em áreas específicas/pontuais é que as mudanças globais são concretizadas. Portanto, Zanzarini (2008) ratificou esta ideia quando ressalta que a partir de medidas que resultam em pequenas mudanças, é possível a construção de melhorias significativas num contexto macro.

No decorrer e posteriormente ao desenvolvimento dos trabalhos, os produtores rurais constataram a seriedade e importância destes. E, após a recuperação da área proposta, o cercamento foi considerado um instrumento mitigador e indispensável, pois estes contribuem diretamente com o equilíbrio da microbacia e manutenção do ciclo hidrológico. Desta forma, Castro (2015) reitera que o manejo adequado solo evita que ocorram perdas excessivas de água através do escoamento superficial, o que favorece à infiltração e abastece os reservatórios subterrâneos e, assim, é garantido o 
suprimento de água disponível para atividades agrossilviculturais.

Para os produtores, a realização deste trabalho associado a encontros e ações ativas nas áreas implantadas serve para fortalecer a questão ambiental na região. Em uma propriedade na vila 17 de Abril, o depoimento de um assentado (Quadro $1)$.

Quadro 01. Depoimento de um assentado após os primeiros resultados decorrentes da aplicação da técnica de recuperação.

"Aprendi muito, fico muito feliz. A gente
roçava, derrubava e queimava tudo pra depois
plantar. E água é importante para plantar na
roça. Com o passar do tempo a água estava
sumindo das áreas plantadas. As pessoas não
acreditam que o que vem da natureza ajuda,
mas gostei muito do que foi feito, é mais
prático para trabalhar e terei água para eu
ajudar pra quem não tem na sua terra"
(informação verbal).

$\mathrm{O}$ envolvimento dos produtores rurais e seus familiares ofereceram suporte à atividade em suas propriedades bem como demonstraram mudanças de compreensão ambiental. A conscientização dos produtores rurais assentados da região foi dificultada pelo isolamento das nascentes, estabelecido por Brasil (2012), que representa redução de área disponível, principalmente para a pecuária, pois o a área, em duas propriedades (P3 e P5), são utilizadas para dessedentação e alimentação dos animais. No entanto, além do cumprimento da legislação, de acordo com Pinto et al. (2005), este cercamento evita a compactação do solo pelo pisoteio de animais e o comprometimento do estrato vegetal regenerativo da área, e estes fatores foram elencados, justificados e discutidos durante a palestra ministrada.

Assim, o bem-estar real dos agricultores após o término de conservação das nascentes e a discussão de melhorias que cada um apresenta, mostra o grau de aprendizado a partir de práticas educativas. Este fator corrobora com as questões ambientais quando trabalhadas esmeradamente e envolvendo a comunidade, colaborando com resultados excelentes.

\section{CONCLUSÕES}

As ações antrópicas realizadas para a produção agropecuária influenciam de maneira negativa as nascentes, sendo o principal agente causador da degradação no entorno das mesmas. A justificativa para a degradação é a necessidade de expansão das atividades de agropecuária para uso alternativo do solo.

A Educação Ambiental com os assentados sinalizou, por meio da compreensão, da reflexão e do diálogo entre seus atores os elementos que consistiriam na autêntica melhoria da recuperação ambiental.

\section{REFERÊNCIAS}

ALTIERI, M. A. Agroecologia, agricultura camponesa e soberania alimentar. Revista do Núcleo de Estudos, Pesquisas e Projetos de Reforma Agrária (NERA), n. 16, 2010. Disponível <http://www2.fct.unesp.br/nera/revistas/16/7_altieri.pdf>. Acesso em: 17 jun. 2015.
BRASIL. Lei Federal n ${ }^{\circ} 12.651$ de 25 de maio de 2012. Disponível

<http://www.planalto.gov.br/ccivil_03/_ato2011-

2014/2012/lei/l12651.htm>. Acesso em: 15 jun. 2015.

BRASIL. Ministério do Meio Ambiente. Água: manual de uso. Brasília, DF, 2006. Disponível em: < http://www.comiteibicui.com.br/artigos/Manual\%20de\%20Us o\%20da\%20Agua.pdf>. Acesso em: 13 ago. 2015.

CALHEIROS, R. O. Cadernos da Mata Ciliar. São Paulo: Ministério do Meio Ambiente, 2006. Disponível em: <http://www.ambiente.sp.gov.br/municipioverdeazul/files/20 13/05/Cadernos-de-Mata-Ciliar-

1_Preserva\%C3\%A7\%C3\%A3o-e-

recupera\%C3\%A7\%C3\%A3o-de-nascentes_2004.pdf>.

Acesso em: 17 jul. 2015.

CASTRO, P. S. Recuperação e Conservação de Nascentes. Viçosa, MG: Centro de Produções Técnicas, 2015.

DE'CARLI, C. Sonhos de Abril: A Luta pela Terra e a Reforma Agrária no Brasil e em Portugal - os Casos de Eldorado dos Carajás e Baleizão. Coimbra: Universidade de Coimbra, 2014.

IBGE. Instituto Brasileiro de Geografia e Estatística. Censo Demográfico 2010. Rio de Janeiro: IBGE, 2010. Disponível em:

http://cidades.ibge.gov.br/xtras/perfil.php?codmun=150295>. Acesso em: 13 nov. 2015.

IBGE. Instituto Brasileiro de Geografia e Estatística. Eldorado dos Carajás: senso populacional. 2010. Disponível em:

<http://biblioteca.ibge.gov.br/visualizacao/dtbs/para/eldorado doscarajas.pdf $>$. Acesso em: 12 jun. 2015.

MINC, C. Ecologia e Cidadania. São Paulo, SP: Moderna, 2005.

PEREIRA, L. C. Uso e Conservação de Nascentes em Assentamentos Rurais. 2012. 181 f. Dissertação (Mestrado em Engenharia Civil) Universidade Federal de Pernambuco, Recife, PE, 2012.

PINTO, V. A. P.; BOTELHO, S.A.; OLIVEIRA FILHO, A. T.; DAVIDE. Estudo da vegetação como subsídios para propostas de recuperação das nascentes da bacia hidrográfica do Ribeirão Santa Cruz, Lavras, MG. Revista Árvore, v. 29, n.5, 2005 .

SANTOS, B. S.; CRISPIM, J. Q. Recuperação e Preservação de Nascentes: uma Alternativa de Melhoria Socioambiental para Pequenos Agricultores da Comunidade Barreiro das Frutas - Campo Mourão - PR. Cesumar: 2011. Disponível em:

<http://www.cesumar.br/prppge/pesquisa/epcc2011/anais/bru na_srutkowiski_santos.pdf>. Acesso em: 17 jul. 2015.

ZANZARINI, R. M. Recuperação de uma nascente no município de Araguari/MG por meio da técnica de recuperação natural: uma proposta de avaliação, recuperação e educação ambiental. Trabalho de Conclusão de Curso (Graduação) Universidade Federal de Uberlândia, Uberlândia, 2008. 